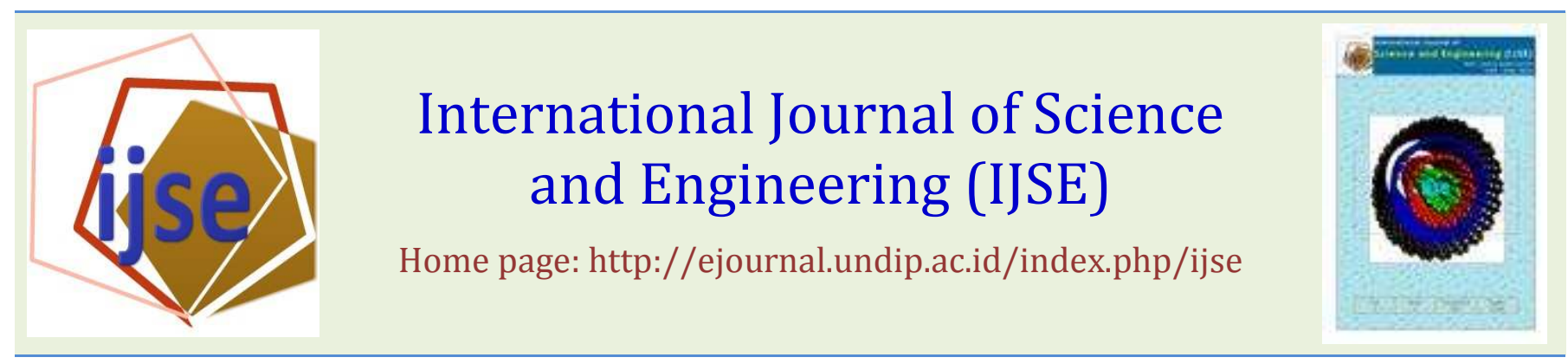

\title{
Potential of an asymmetrical agitation in industrial mixing
}

\author{
Kazuhiko Nishi ${ }^{*}$, Naoki Enya², Kazufumi Sonoda², Ryuta Misumi¹, Meguru Kaminoyama1 \\ 1 Department of Materials Science and Chemical Engineering, Yokohama National University, 79-5 Tokiwadai, Hodogaya, \\ Yokohama, 240-8501, Japan \\ 2 Department of Materials Science and Chemical Engineering, School of Engineering, Yokohama National University, 79-5 \\ Tokiwadai, Hodogaya, Yokohama, 240-8501, Japan \\ Coorresponding Author: nishi@ynu.acjp
}

\begin{abstract}
Mixing is one of the most fundamental operations in chemical engineering. Stirred tanks are widely used in the manufacture of such materials as chemicals, paints, inks, electronics materials, ceramics, foods, pharmaceuticals and cosmetics. Suitable mixing is indispensable to the purpose achievement of a process. Eccentric mixing, in which an impeller installed at eccentric position in a vessel, is one of the traditional methods of promoting mixing. An asymmetrical flow which occurs in vessel is complicated, and it promotes mixing, distribution, and mass transfer. In this study, a new mixing method which eccentric mixing using a large type impeller which attracts attention in recent years is shown. The high performance of a large impeller can be combined with the advantages of an eccentric impeller by using the impeller at an eccentric position. The power consumption and mixing time for MAXBLEND, which is a type of large impeller, were investigated. The power consumption, $P$, and mixing time, $\theta_{\mathrm{M}}$, were measured under various eccentric conditions. The relation between the power number $\left(N_{\mathrm{p}}\right)$ and Reynolds number $(R e)$ and that between the dimensionless mixing time $\left(n \theta_{\mathrm{M}}\right)$ and $R e$ were investigated. When eccentric mixing is used industrially, we should be concerned about the horizontal load to a agitating shaft. The large oscillating horizontal load causes serious problems, such as the falling off of the impeller or the breakage of the motor, mechanical seal or gearbox. It is, therefore, important to understand the relation between these values and the impeller rotational speed when designing the mixing equipment and determining the operating conditions. In this study, the torque and horizontal load were measured in eccentric mixing under various eccentric conditions. The averages of both, the torque and the horizontal load, and their standard deviations, corresponding to the amplitude of fluctuation, were shown.
\end{abstract}

Key words - eccentric mixing, large type impeller, torque, horizontal load

Submission: September 17, $2013 \quad$ Corrected : October 6, 2013

Accepted: October 10, 2013

Doi: 10.12777 ijse.5.2.73-80

[How to cite this article: Nishi, K., Enya, N., Sonoda, K., Misumi, R., Kaminoyama, M. (2013). Potential of an asymmetrical agitation in industrial mixing. International Journal of Science and Engineering, 5(2),73-80. Doi: 10.12777/ijse.5.2.73-80]

\section{Introduction}

Various kinds of large impellers, such as FULLZONE (Kobelco Eco-Solutions Co., Ltd.), Super-Mix MR205 (Satake Chemical Equipment Mfg Co., Ltd.), Hi-F mixer (Soken Tecnix Co., Ltd.) and MAXBLEND (Sumitomo Heavy Industries Co., Ltd.), have been developed in Japan. Since these impellers have a high mixing performance over a wide range of viscosities, they are used in mixing, dispersion, reaction and polymerization processes [1-5]. Recently, their use in the food and pharmaceutical industries is being considered [6, 7]. For agitation in the turbulent region, these large impellers are usually used with baffles to promote mixing. However, baffles often cause problems for washing and sterilization. Furthermore, in the laminar region, baffles are not effective for mixing, and in fact, they often obstruct mixing. Eccentric mixing is one of the traditional methods of promoting mixing in a vessel without baffles. An eccentrically located impeller generates a vertical flow, which contributes to mixing, without baffles $[8,9]$. If a large impeller is used at an eccentric position, it is expected that the high performance of the large impeller can be combined with the advantages of an eccentric mixer [10].

In this study, a MAXBLEND impeller was investigated as an example of a large impeller. The power consumption and mixing time of a MAXBLEND impeller were measured under various eccentric conditions. Furthermore, the mixing performance based on the power consumption of eccentric mixing with a MAXBLEND impeller was investigated. 


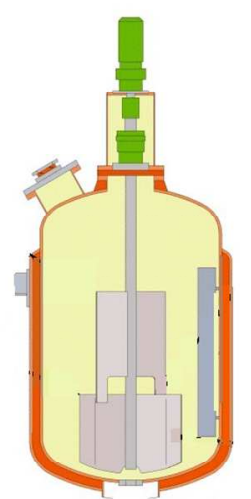

FULLZONE

(Kobelco Eco-Solutions Co., Ltd.)

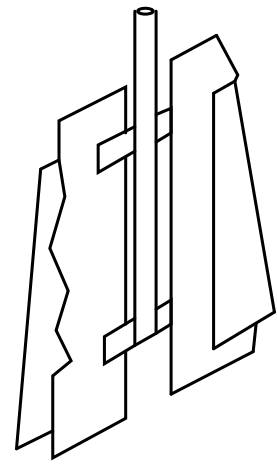

Super-Mix MR205

(Satake Chemical Equip. Mfg Co., Ltd.)

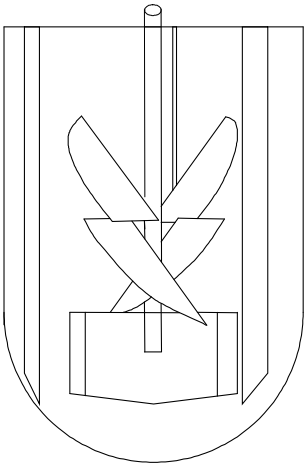

Hi-F mixer

(Soken Tecnix Co., Ltd.)

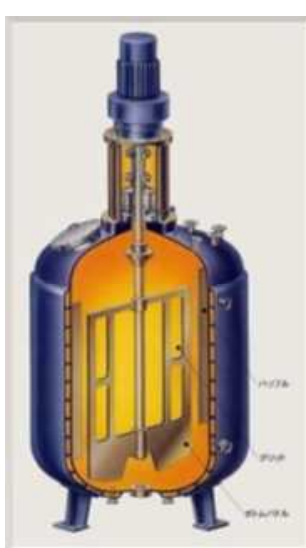

Maxblend

(Sumitomo Heavy

Industries Co., Ltd)

Fig. 1 Various kind of large-type impeller

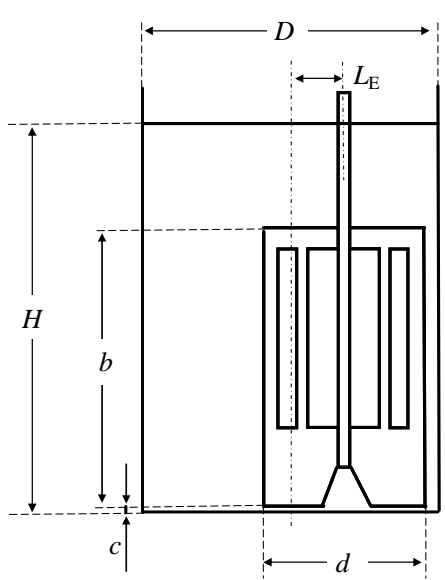

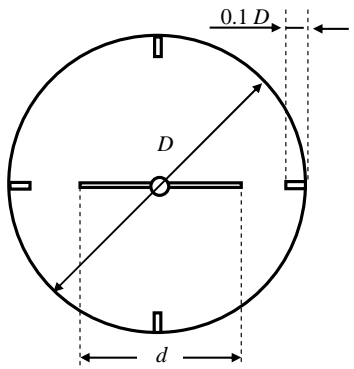

(b) Baffit condition

Table 1 Dimension of Vessel and Impeller

\begin{tabular}{|l|c|}
\hline Diameter of Vessel, $D[\mathrm{~m}]$ & 0.200 \\
\hline Depth of Liquid, $H[\mathrm{~m}]$ & 0.239 \\
\hline Diameter of Impeller, $d[\mathrm{~m}]$ & 0.108 \\
\hline Width of Impeller, $b[\mathrm{~m}]$ & 0.196 \\
\hline Clearance from Impeller to Bottom, c $[\mathrm{m}]$ & 0.003 \\
\hline Eccentric Length, $L_{\mathrm{E}}[\mathrm{m}]$ & $0.01-0.04$ \\
\hline
\end{tabular}

(a) Side view of eccentric mixing

Fig. 1 Schematic diagram of the experimental apparatus

When eccentric mixing is used industrially, we should be concerned about the horizontal load to a agitating shaft. It is expected that the average torque and horizontal load on agitating shaft are larger than in the concentric mixing without baffles. Since these values fluctuate with the rotation of the impeller, the instantaneous maximum value is still larger. The large, fluctuating torque and horizontal load can cause serious problems, such as the falling off of the impeller or the breakage of the shaft, motor, mechanical seal or gearbox. It is, therefore, important to understand the relation between these values and the impeller rotational speed when designing the mixing equipment and determining the operating conditions.

In this study, the torque and horizontal load were measured in eccentric mixing using a MAXBLEND impeller, as an example of a large impeller, at various impeller rotational speeds and under various eccentric conditions in a turbulent state. The average torque and standard deviation, corresponding to the amplitude of fluctuation were calculated, and the cause of the fluctuation was investigated by FFT analysis.

\section{Power Consumption and Mixing Performance in an Eccentric Mixer with a MAXBLEND Impeller 1.1 Experiment}

Figure 1 shows a schematic diagram of the experimental apparatus. Some dimensions of the vessel and impeller in eccentric mixing are shown in Table 1. A cylindrical vessel with a $0.200 \mathrm{~m}$ diameter, $D$, and a flat bottom was used. The diameter of the impeller, $d$ was $0.108 \mathrm{~m}$. The eccentric length, $L_{\mathrm{E}}$, was defined as the distance of the rotation shaft from the centerline of the vessel. The MAXBLEND impeller was installed at $L_{\mathrm{E}}=0.01$ - $0.04 \mathrm{~m}$ in the vessel, without baffles. Mixing by the impeller at a concentric position $\left(L_{\mathrm{E}}=0.00\right)$ without baffle or with four baffles was compared with eccentric mixing. In concentric mixing, the vessel diameter, liquid height, diameter and width of impeller and clearance from impeller to bottom were the same as eccentric mixing. In the case of concentric mixing with baffles, the width of baffle was $0.02 \mathrm{~m}$.

Water and glycerol, at fixed concentrations, were used as the mixing liquids. The viscosity, ? solutions ranged from $0.98 \times 10^{-3}$ to $0.95 \mathrm{~Pa} \cdot \mathrm{s}$. The depth 
of the mixing liquid during the experiment was $0.239 \mathrm{~m}$. The clearance from the bottom to the lower end of the impeller and the distance from the upper end of impeller to the liquid surface were $0.003 \mathrm{~m}(0.015 \mathrm{D})$ and $0.04 \mathrm{~m}$ $(0.2 D)$, respectively.

Power consumption of the impeller was measured with a torque meter (Satake Chemical Equipment Mfg Ltd.; ST-3000). This equipment can measure the torque on the agitating shaft in the mixing liquid without mechanical friction by correcting, using the torque value previously measured in air. Power consumption, $P$, was calculated by Eq. (1) from the impeller rotational speed, $n$, and the average of the torque, $T$, measured for 120 seconds at each condition.

\section{$P=2$ ? $n T$}

Mixing time was measured by a decolorization method using iodine and sodium thiosulfate. The mixing liquid in the vessel was colored by adding $0.010 \mathrm{~L}$ of the $0.5 \mathrm{~mol} / \mathrm{L}$ iodine solution $\left(8.0 \times 10^{-4} \mathrm{~mol} / \mathrm{L}\right)$, and mixing with a sufficiently large impeller rotational speed. The $0.012 \mathrm{~L}$ of $1.0 \mathrm{~mol} / \mathrm{L}$ sodium thiosulfate solution $(1.2$ chemical equivalent to iodine) was injected, and decolorization started. In eccentric mixing, the sodium thiosulfate solution was injected at a point midway between the shaft and the vessel wall, on the side opposite to the eccentric direction. Mixing time, ? ${ }_{\mathrm{M}}$, was determined based on a video image.

\subsection{Results and Discussion}

\subsubsection{Power Consumption of Eccentric Mixing}

The power consumption in neat glycerol was proportional to the square of the impeller rotational speed. It was presumed that the flow state was laminar. The change in power consumption with the eccentric length was small. The power consumption at $L_{\mathrm{E}}=0.04 \mathrm{~m}$ was slightly larger than that of concentric mixing with baffles. The power consumption in water was smaller than that in glycerol, and it was proportional to the cube of the impeller rotational speed. This indicates that flow was in a turbulent state. When the eccentric length increased, the power consumption increased. The power consumption at $L_{\mathrm{E}}=0.04 \mathrm{~m}$ was almost the same as that of baffled mixing.

In Figure 2, the relation between the impeller rotational speed and the power consumption was shown by the correlation of the Reynolds number, $\operatorname{Re}\left(=\right.$ ? $n d^{2} /$ ? $)$ and power number, $N_{\mathrm{p}}\left(=P /{ }^{2} n^{3} d^{5}\right)$. In the laminar region, $N_{\mathrm{p}}$ of eccentric mixing decreased linearly with increasing $R e$ on a logarithmic graph. The slope of $N_{\mathrm{p}}$ against $R e$ was approximately -1 . When $L_{\mathrm{E}}$ was large, $N_{\mathrm{p}}$ was large. The difference between $N_{\mathrm{p}}$ of eccentric mixing and $N_{\mathrm{p}}$ of concentric mixing with and without baffles was small. It was interesting that the power consumption at $L_{\mathrm{E}}$ $=0.04 \mathrm{~m}$ was larger than that of concentric mixing with baffles. In the turbulent region ( $R e>2000), N_{\mathrm{p}}$ at $L_{\mathrm{E}}=0.01$ and $0.02 \mathrm{~m}$ decreased linearly with increasing $R e$. This behavior was similar to that of concentric mixing without baffles. On the other hand, the values of $N_{\mathrm{p}}$ at $L_{\mathrm{E}}=0.03$ and $0.04 \mathrm{~m}$ were constant. This behavior was similar to that of concentric mixing with baffles. Since $N_{\mathrm{p}}$ at $L_{\mathrm{E}}=0.03$ and $0.04 \mathrm{~m}$ was independent of $R e$, it was presumed from the power consumption that a turbulent state was established throughout the whole of the vessel. In eccentric mixing, since a vortex, which was very large in concentric mixing without baffles, was not generated near the mixer shaft, it was presumed that the generation of a cylindrical rotating zone [8] was inhibited. In this region, $N_{\mathrm{p}}$ of eccentric mixing was clearly larger than that of concentric mixing without baffles $\left(L_{\mathrm{E}}=0\right)$. It was, thus, confirmed that a large amount of energy can be supplied to the mixing liquid in eccentric mixing.

\subsubsection{Mixing Time of Eccentric Mixing}

The mixing time was considered a non-dimensional quantity, given by $n$ ? $_{\mathrm{M}}$. The relation between $n$ ? $_{\mathrm{M}}$ and $R e$ is shown in Figure 6. In the region where $R e<2000$, when $R e$ increased, $n$ ? $_{\mathrm{M}}$ decreased. In this region, which was considered to be in a laminar or a transition state, the value of $n$ ? ? $_{\mathrm{M}}$ of eccentric mixing was smaller than that of concentric mixing with and without baffles. The eccentric impeller generated asymmetrical flow, which promoted mixing. On the other hand, in the region where $R e>2000$, the value of $n$ ? ${ }_{\mathrm{M}}$ was almost constant for each value of $L_{\mathrm{E}}$. This was characteristic of a turbulent state. In this region, the value of $n$ ? $_{\mathrm{M}}$ of eccentric mixing was clearly smaller than that of concentric mixing without baffles. The $n$ ? $_{\mathrm{M}}$ at $L_{\mathrm{E}}=0.01-0.03 \mathrm{~m}$ of eccentric mixing was larger than that of concentric mixing with baffles. However, the value of

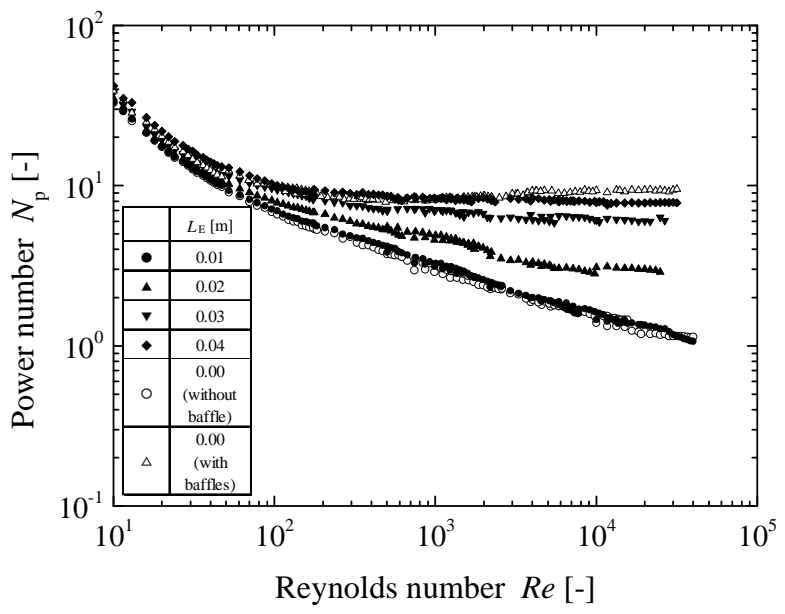

Fig. 2 Relation between $N_{\mathrm{p}}$ and $R e$

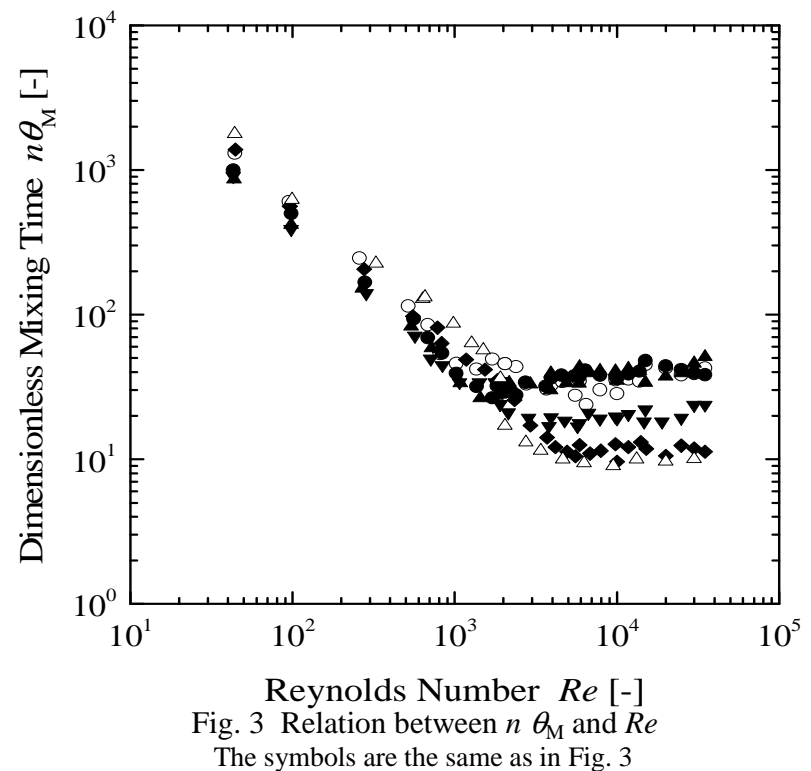


$n$ ? $_{\mathrm{M}}$ at $L_{\mathrm{E}}=0.04 \mathrm{~m}$ was almost the same as that of concentric mixing with baffles. Turbulent diffusion dominated $n$ ? ? $_{\mathrm{M}}$ during mixing in a turbulent state. It was predicted that the turbulence intensity of eccentric mixing would be lower than that of concentric mixing with baffles.

\section{Torque and Horizontal Load on an Agitating Shaft in an Eccentric Mixer with a MAXBLEND Impeller 2.1 Experiment}

Figure 4 shows a schematic diagram of the experimental apparatus and its dimensions. A non-baffled, cylindrical vessel with a $0.31 \mathrm{~m}$ diameter, $D$, and a dished bottom was used. The MAXBLEND impeller is a gate-type impeller with a wide, 2-blade paddle at the bottom. The diameter, $d$, and height, $h$, of the impeller were $0.165 \mathrm{~m}$ and $0.305 \mathrm{~m}$, respectively. The diameter, $d_{\mathrm{S}}$, and length, $L_{\mathrm{S}}$, of the agitating shaft, which influences the sensitivity of the measurement of the torque and horizontal load, were $0.015 \mathrm{~m}$ and $0.58 \mathrm{~m}$, respectively. The impeller was installed at a position where the distance between the lower end of the impeller and the bottom of the vessel, $c$, was $0.060 \mathrm{~m}$. Water was used as the mixing medium and the vessel was filled to a height $0.062 \mathrm{~m}(0.2 \mathrm{D})$ above the upper end of the impeller. The eccentric length, $L_{\mathrm{E}}$, was defined as the distance of the rotation shaft from the centerline of the vessel. The eccentric ratio, $r_{\mathrm{E}}$ was defined by Eq. (2), based on $L_{\mathrm{E}}, D$ and $d$, and this value was used in calculations based on the data.

$$
r_{\mathrm{E}}=\frac{L_{\mathrm{E}}}{(D-d) / 2}
$$

The impeller rotational speed was set as the range of 1 to $4 \mathrm{~s}^{-1}$. In this case, Reynolds number, $R e_{\mathrm{d}}$ ( = ? $n d^{2} /$ ? $)$, was between 27200 and 122500 , and these values show that a flow state in the vessel was turbulent.

The torque and horizontal load were measured with strain gauges affixed to the shaft. To measure the torque, the strain on the shaft in the direction of rotation was measured with strain gauges (PCF-02-35S4-T3-44, Toyo Sokki Co., Ltd.) affixed to the shaft at an angle of 45 degrees. The strain, ? , was converted to torque, $T$, using Eq. (3) prepared based on the strain and the torque measured with a torque meter (PKF-01-35S5-44, Toyo Sokki Co., Ltd.).

$$
T=50.1 \varepsilon
$$

To measure the horizontal load, the strain in the $\mathrm{x}$ direction and y-direction, shown in Figure 1, were measured with strain gauges affixed to the shaft in each direction. In this study, the $\mathrm{x}$-direction was the direction parallel to the blade of the impeller, and the y-direction was the direction perpendicular to the blade. The strain in each direction, ? $?_{\mathrm{x}}$ or $?_{\mathrm{y}}$, were converted to horizontal load, $F_{\mathrm{x}}$ or $F_{\mathrm{y}}$, by Eq. (4) based on the mechanics of materials.

$$
F_{\mathrm{i}}=0.1132 \varepsilon_{\mathrm{i}} \quad(i=x, y)
$$

A 4-gauge method, which involved a bridged circuit comprising four strain gauges, was used to measure the strain in each direction accurately. The output voltage of the bridged circuit was transferred through a radio system (TWI-701 \& TWT, Toyo Sokki Co., Ltd.), and was analyzed by computer. The time interval of the data transfer, which was the time resolution of the measurement, was $0.0125 \mathrm{~s}$
(80 Hz). Measurement continued for $240 \mathrm{~s}$ or more at each impeller rotational speed, $n$, and eccentric length. The number of the data used for FFT analysis was $2^{14}=16384$ (204.8 s).

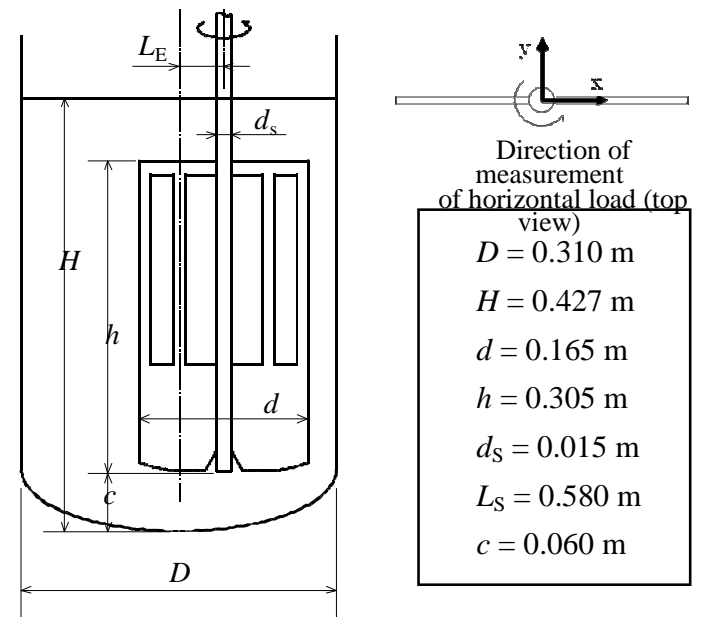

Fig. 4 Experimental apparatus

\subsection{Results and Discussion \\ 2.2.1 Torque of eccentric mixing}

In Figure 5, the time series of the torque, $T$, for several eccentric conditions at $n=2.0 \mathrm{~s}^{-1}$ is shown. In these figures, part of the time series is expanded and shown. The fluctuation of the torque at $r_{\mathrm{E}}=0.00$ (concentric mixing without baffles) shown in Figure $\mathbf{5 ( a )}$ is complicated. In this case, the Reynolds number, $R e$, is 54450 , and turbulent flow in the vessel generated an fluctuation. At $r_{\mathrm{E}}=0.11$ (Figure 5(b)), although the time series of the torque was slightly periodic, the difference from that at $r_{\mathrm{E}}=0.00$ was small. In the range, $r_{\mathrm{E}}=0.22-$ 0.65 (Figure 5(c)), when $r_{\mathrm{E}}$ increased, the average torque increased. It was apparent that fluctuation of torque was periodic and the amplitude of fluctuation increased with the increase in $r_{\mathrm{E}}$.

In Figure 6, the FFT analysis of the torque data at $n=$ $2 \mathrm{~s}^{-1}$ is shown. The data for $204.8 \mathrm{~s}\left(2^{14}=16384\right.$ points $)$ was used for the FFT, and the time interval in the analysis was $0.0125 \mathrm{~s}(80 \mathrm{~Hz})$. The tendency of the FFT analysis shown below was seen to be similar to that at other impeller rotational speeds. In the FFT analysis result at $r_{\mathrm{E}}$ $=0.00$ (Figure. 6(a)), a characteristic, broad peak was observed in the frequency, $f=2.4 \mathrm{~Hz}(=1.2 n)$. Although the cause of this peak was not known, It was guessed that the random flow and the eddy which occurs asymmetrically in a turbulent mixing were related. In addition, the low frequency fluctuation of the flow (Letellier et al., 1997, Matsuda et al., 2003) generated in the vessel may be related together. At $r_{\mathrm{E}}=0.11$ (Figure 6(b)), a peak at $f=4 \mathrm{~Hz}$, in addition to the peak at $f=2.4$ $\mathrm{Hz}$, appeared. Since this peak at $f=4 \mathrm{~Hz}$ was very sharp, it is doubtful that this peak was generated by flow phenomena. In eccentric mixing with a MAXBLEND impeller, which has two blades, and since the blades approach the vessel wall twice during each rotation, the torque fluctuates with a frequency of $2 n[\mathrm{~Hz}]$. It is expected that the fluctuation which originated in the flow and the mechanical fluctuation overlap at $r_{\mathrm{E}}=0.11$. When 
$r_{\mathrm{E}}$ increases (Figures. 6(c) - (e)), the peak at $f=2 n$ becomes larger and the fluctuation in flow decreases proportionately. At $r_{\mathrm{E}}=0.44$ and 0.65 , a sharp peak also appeared at $f=2 \mathrm{~Hz}(=n)$, and the mechanical fluctuation dominated the torque behavior.

In Figure 7 (a), the relation between the average of torque, $T_{\text {ave, }}$ and the rotational speed are shown on a log$\log$ plot. At each $r_{\mathrm{E}}, T_{\text {ave }}$ is almost proportional to the square of $n$. This is typical behavior in turbulent mixing. In Figure 7 (b), the relation between $T_{\text {ave, and }} r_{\mathrm{E}}$ are shown on a semi-log plot. $T_{\mathrm{ave}}$ at $r_{\mathrm{E}}=0.00$ (concentric mixing without baffle) and $r_{\mathrm{E}}=0.11$ are almost equal. It was considered probable that the influence of the flow on $T_{\text {ave }}$ was large at $r_{\mathrm{E}}=0.11$. In the region of $r_{\mathrm{E}} \geq 0.11, T_{\text {ave }}$ increased exponentially with $r_{\mathrm{E}}$, and the gradients of the lines were almost the same. Based on these data, the correlation equation,

$$
T_{\text {ave }}=9.1 \times 10^{-3} n^{2.0} \exp \left(4.6 r_{\mathrm{E}}\right)(5)
$$

was obtained.

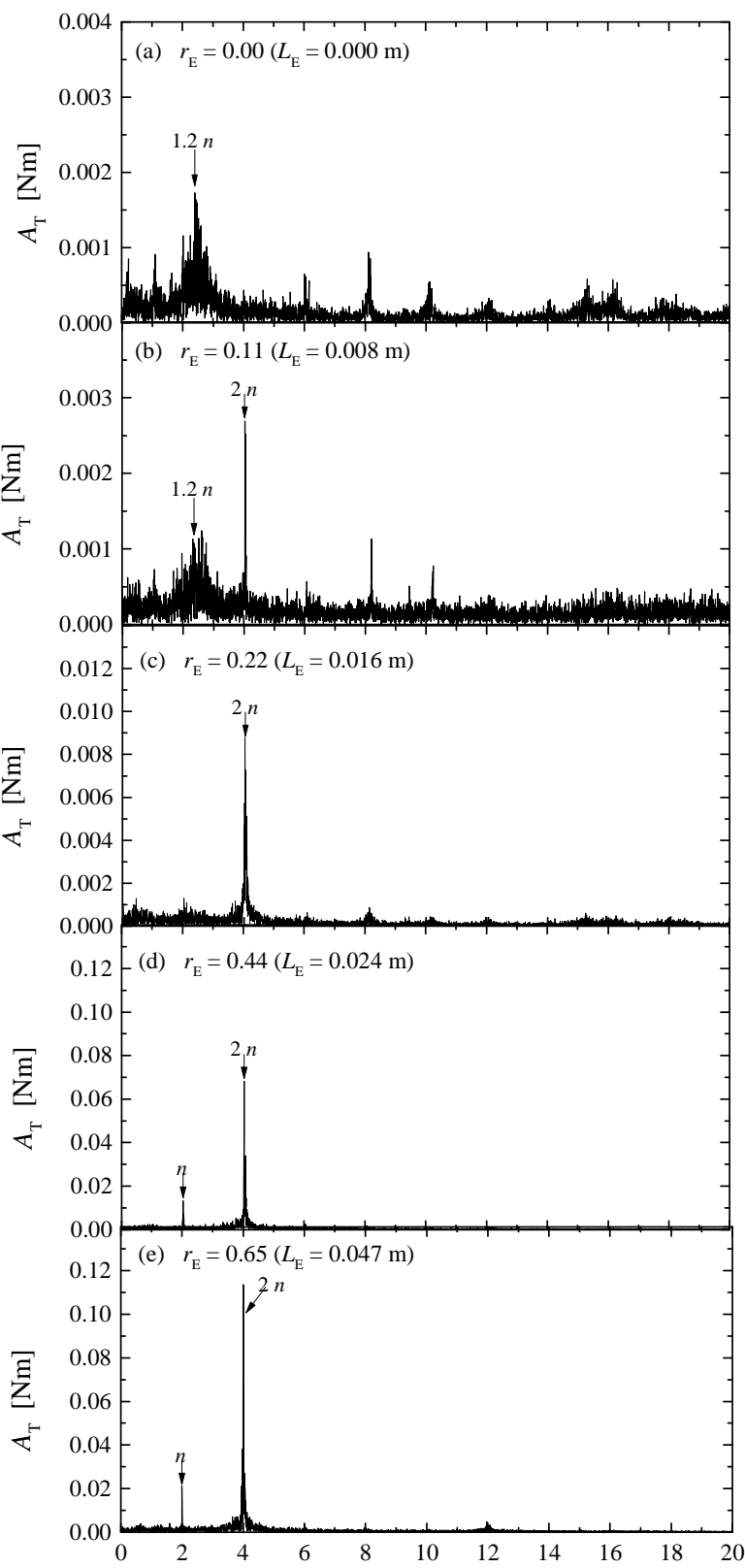

Fig. 6 FFT analysis of torque under various eccentric conditions at $n=2 \mathrm{~s}^{-1}$

with $T_{\text {ave, each }} T_{\text {std }}$ was $15 \%$ or less of $T_{\text {ave }}$ at the same $r_{\mathrm{E}}$ and $n$. In the design of a shaft diameter in an eccentric mixer using a MAXBLEND impeller, it is necessary to prepare larger torque than $T_{\text {ave }}$ based on $T_{\text {std. }}$.
The relation between the standard deviation of the torque, $T_{\text {std }}$, which corresponds to the amplitude of the torque fluctuation, and $r_{\mathrm{E}}$ at each $n$ is shown in Figure 8. $T_{\text {std }}$ increased with the increase in $r_{\mathrm{E}} . T_{\mathrm{std}}$, particularly increased greatly at $r_{\mathrm{E}}=0.44$. When $T_{\text {std }}$ was compared 


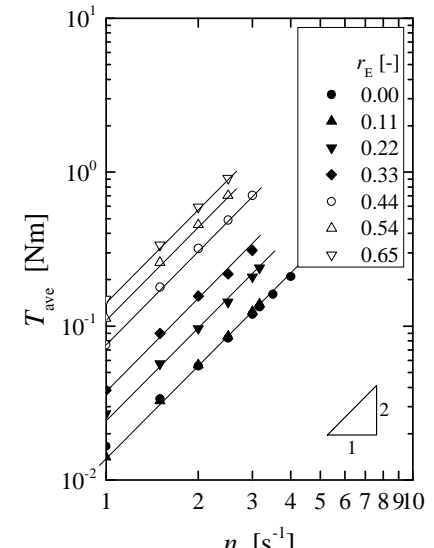

(a) Rotational speed

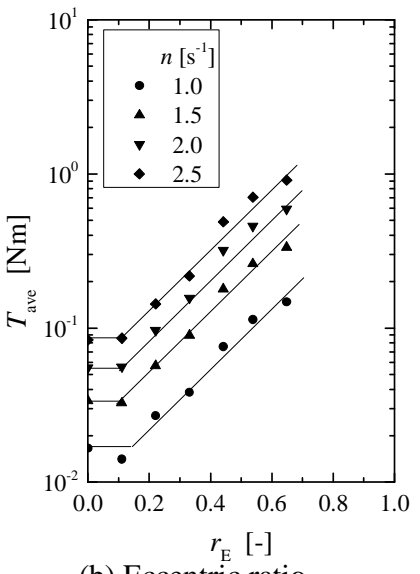

(b) Eccentric ratio

Fig. 7 Relation between torque average and impeller rotational speed, and between torque average and eccentric ratio

\subsubsection{Horizontal load of eccentric mixing}

In Figure 9, the typical time series of the load in the x-direction, $F_{\mathrm{x}}$, and the load in the y-direction, $F_{\mathrm{y}}$, at $n=2$ $\mathrm{s}^{-1}$ are shown. Figure 9 (a) and (b) are at $r_{\mathrm{E}}=0.00$ and

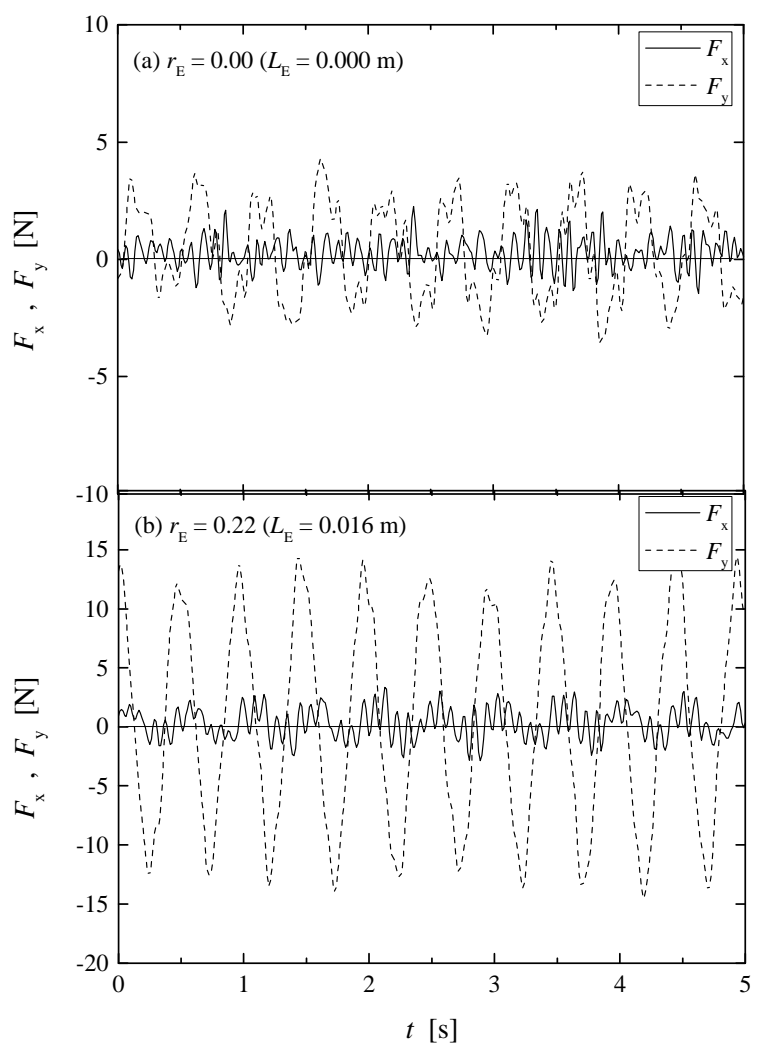

Fig. 9 Time series of horizontal load under various eccentric conditions at $n=2 \mathrm{~s}^{-1}$

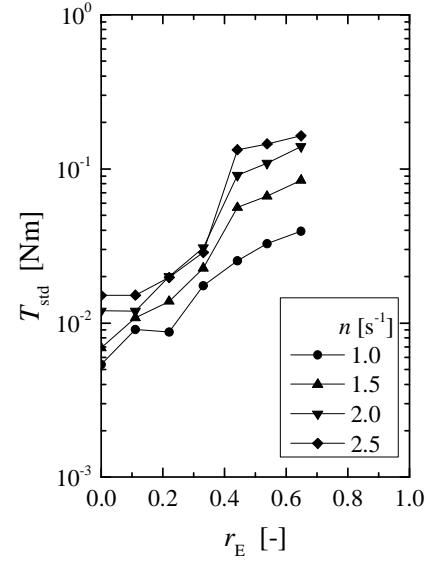

Fig. 8 Relation between standard deviation of torque and eccentric ratio

0.22 respectively. The $F_{\mathrm{x}}$ and $F_{\mathrm{y}}$ were fluctuating between plus and minus, and their average was almost zero in both cases. So, in this study, only fluctuation of the load is discussed. $F_{\mathrm{y}}$, the load perpendicular to the blade, was apparently periodic. $F_{\mathrm{x}}$, the load parallel to the blade was

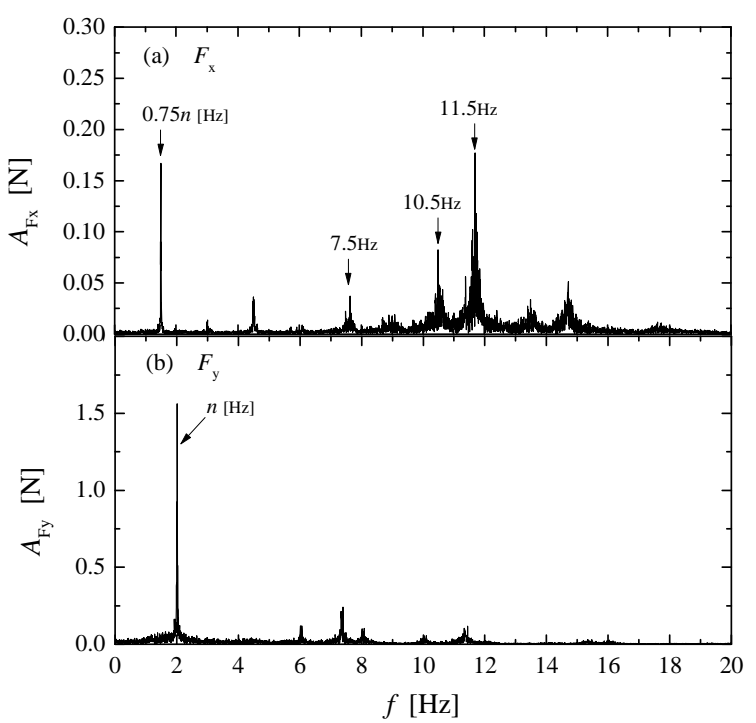

Fig. 10 FFT analysis of horizontal load at $r_{\mathrm{E}}=0.00$

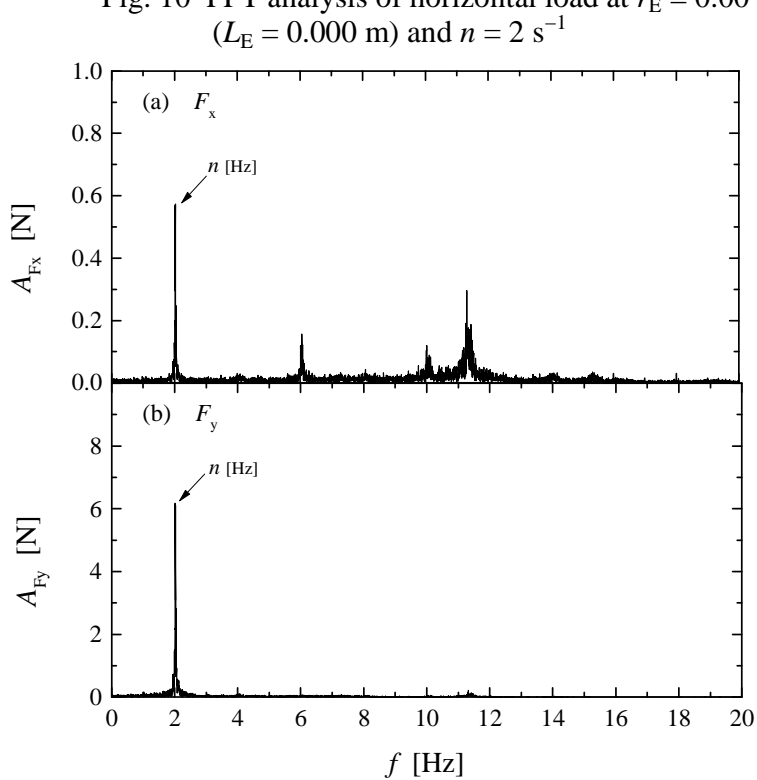

Fig. 11 FFT analysis of horizontal load at $r_{\mathrm{E}}=0.22$ and $n=2 \mathrm{~s}^{-1}$ 


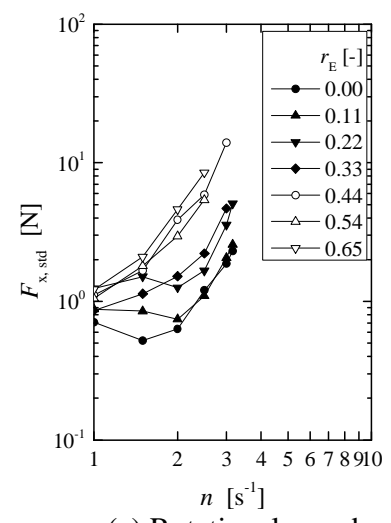

(a) Rotational speed

Fig. 12 Relation between the standa and impeller rotational speed, and between the standard deviation of $F_{\mathrm{x}}$ and eccentric ratio

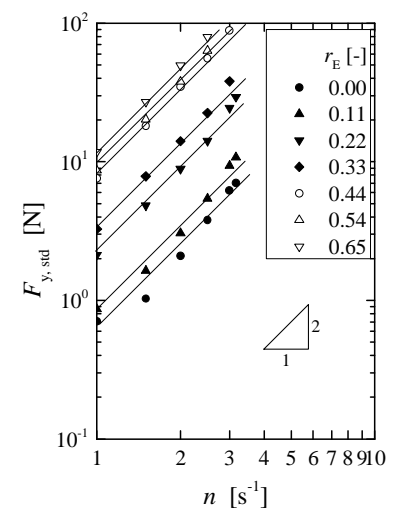

(a) Rotational speed

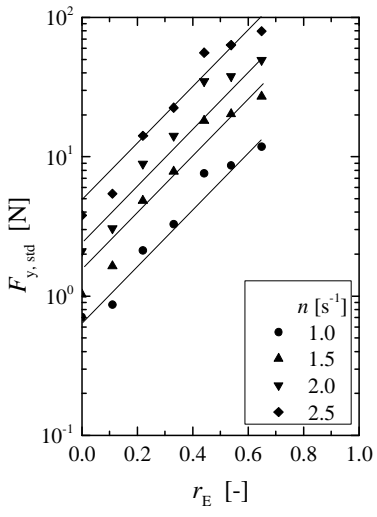

(b) Eccentric ratio

Fig. 13 Relation between the standard deviation of $F_{\mathrm{y}}$ and impeller rotational speed, and between the standard deviation of $F_{\mathrm{y}}$ and eccentric ratio

smaller than $F_{\mathrm{y}}$, and its period was shorter. The cause of $F_{\mathrm{x}}$ was not well understood. It was considered probable that the turbulence caused by the impeller and the vortex behind the blade were related to $F_{\mathrm{x}}$. It was also considered probable that $F_{\mathrm{y}}$ was transmitted in the x-direction by the shaft, which caused strain in the $\mathrm{x}$-direction, and is it was observed as $F_{\mathrm{x}}$.

In Figure 10, FFT analysis at $r_{\mathrm{E}}=0.00$ (concentric mixing without baffles) at $n=2 \mathrm{~s}^{-1}$ is shown as a basis. There were a sharp peak at $1.5 \mathrm{~Hz}(0.75 \mathrm{n})$ and broad peaks at 7.5, 10.5, $11.5 \mathrm{~Hz}$ in FFT of $F_{\mathrm{x}}$. Since the peak at $1.5 \mathrm{~Hz}$ changed simultaneously when the impeller rotational speed changed, this peak was caused by mechanical fluctuation. The peaks at 10.5 and $11.5 \mathrm{~Hz}$ were the characteristic frequencies of the impeller in the $\mathrm{x}$ - and $\mathrm{y}$-directions, and the peak at $7.5 \mathrm{~Hz}$ was the characteristic frequency of the whole mixing apparatus (frame, motor, etc.) FFT of $F_{\mathrm{y}}$ was several times larger than $F_{\mathrm{x}}$. The sharp peak at $2 \mathrm{~Hz}(n)$ was remarkable. Although this peak may have been caused by slight offset of the shaft, that value was small compared with the eccentric mixing shown below. The FFT analysis at $r_{\mathrm{E}}=0.22$ and $n=$ $2 \mathrm{~s}^{-1}$ is shown in Figure 11. The amplitude of $F_{\mathrm{y}}$ was larger than that of $F_{\mathrm{x}}$ and the peak at $2 \mathrm{~Hz}(n)$ was clear in both cases. The strain gauges for measuring $F_{\mathrm{x}}$ and $F_{\mathrm{y}}$ were affixed to the rotational shaft. The peak of $n[\mathrm{~Hz}]$ means that forces in both, positive and negative directions, were loaded on the impeller during each rotation. This corresponded with the blade twice approaching the vessel wall during each rotation. It was found that the horizontal load in eccentric mixing is mechanically generated by the impeller rotation.

In Figure 12 (a), the relation between the standard deviation of $F_{\mathrm{x}}\left(F_{\mathrm{x}, \text { std }}\right)$ and $n$ is shown on a $\log$-log plot. $F_{\mathrm{x}, \text { std }}$ increased with the increase in $n$. The change of $F_{\mathrm{x} \text {, std }}$ was small in the region of $r_{\mathrm{E}}=0.00-0.22$ and $n=1-2 \mathrm{~s}^{-1}$. Since the FFT analysis under these conditions was similar to that in Figure 10 (a), the fluctuation originated as a flow phenomenon. The influence of $n$ on flow-induced fluctuation is different than mechanically induced fluctuation. In Figure 12 (b), the relation between $F_{\mathrm{x} \text {, std }}$ and $r_{\mathrm{E}}$ is shown on a semi-log plot. Although $F_{\mathrm{x}}$, std increased when $r_{\mathrm{E}}$ increased, each gradient changed with $n$. The tendency of $F_{\mathrm{x} \text {, std }}$ in concentric mixing without baffles differs from that in eccentric mixing. Additionally, the mixing at $r_{\mathrm{E}}=0.22$ had a peak, which suggested that the cause of the fluctuation changed.

In Figure 13, the standard deviation of $F_{\mathrm{y}}\left(F_{\mathrm{y}, \mathrm{std}}\right)$ is similarly shown. $F_{\mathrm{y}, \text { std }}$ was one order larger than $F_{\mathrm{x}, \text { std. }} F_{\mathrm{y}, \text { std }}$ was proportional to the power of $n$, and the logarithm of $F_{\mathrm{X} \text {, std }}$ was proportional to $n$.

Based on FFT analysis, the cause of the fluctuation of $F_{\mathrm{y}}$ was considered to be mechanical, and $F_{\mathrm{y} \text {, std }}$ was directly dependent on $n$ and $r_{\mathrm{E}} . F_{\mathrm{y} \text {, std }}$ was expressed by the power function of $n$, and the exponential function of $r_{\mathrm{E}}$.

$$
F_{\mathrm{y}, \mathrm{std}}=0.56 n^{2.2} \exp \left(5.1 r_{\mathrm{E}}\right)
$$

It is necessary in designing equipment to estimate the resultant load of $F_{\mathrm{x}}$ and $F_{\mathrm{y}}$. Based on the time series of $F_{\mathrm{x}}$ and $F_{\mathrm{y}}$ measured simultaneously, the resultant load, $F_{\mathrm{xy}}$, was estimated by Eq. (7),

$$
F_{\mathrm{xy}}=\sqrt{{F_{\mathrm{x}}}^{2}+F_{\mathrm{y}}^{2}}
$$

and Eq. (8) was obtained as a relation between the standard deviation of $F_{\mathrm{xy}}\left(F_{\mathrm{xy}}\right.$, std $)$ and $n, r_{\mathrm{E}}$.

$$
F_{\text {xy, std }}=0.66 n^{2.1} \exp \left(4.9 r_{\mathrm{E}}\right)
$$

The diameter of the agitating shaft in eccentric mixing using a MAXBLEND impeller should be based on the value of the horizontal load estimated by Eq. (5). The value of the strain on the agitating shaft based on estimating the horizontal load is important when such equipment as mechanical seals or gearboxes, is designed.

\section{Conclusions}

In this study, the performance of an eccentrically located MAXBLEND impeller was investigated, based on the power consumption. Furthermore, the torque and horizontal load on the agitating shaft in an eccentric mixer with a MAXBLEND impeller were measured in turbulent state.

For the power consumption, an $N_{\mathrm{p}}-R e$ diagram was generated. In the laminar region, the difference between 
$N_{\mathrm{p}}$ of eccentric mixing and $N_{\mathrm{p}}$ of concentric mixing with and without baffles was small. In the turbulent region $(R e$ $>2000)$, the value of $N_{\mathrm{p}}$ of eccentric mixing was clearly larger than that of concentric mixing without baffles $\left(L_{\mathrm{E}}=\right.$ $0)$. The value of $N_{\mathrm{p}}$ at $L_{\mathrm{E}}=0.01$ and $0.02 \mathrm{~m}$ decreased linearly with increasing $R e$. On the other hand, the values of $N_{\mathrm{p}}$ at $L_{\mathrm{E}}=0.03$ and $0.04 \mathrm{~m}$ were constant. It was presumed that the generation of a cylindrical rotating zone was inhibited. It was, thus, confirmed that a large amount of energy can be supplied to the mixing liquid in eccentric mixing. For the mixing time, an $n$ ? $_{\mathrm{M}}-$ Re diagram was generated. In the region where $\operatorname{Re}<2000$, the value of $n$ ? $_{\mathrm{M}}$ of eccentric mixing was smaller than that of concentric mixing with and without baffles. Furthermore, the values of $\theta_{\mathrm{M}}$ at $L_{\mathrm{E}}=0.02$ and 0.03 were shorter than at other $L_{\mathrm{E}}$. The eccentric impeller generated asymmetrical flow, which promoted mixing. Eccentric mixing under suitable conditions controlled the flow pattern in the vessel and resulted in good mixing. In the region where $\mathrm{Re}>$ 2000 , the value of $n$ ? ${ }_{\mathrm{M}}$ at $L_{\mathrm{E}}=0.04 \mathrm{~m}$ was almost the same as that of concentric mixing with baffles.

The average of torque was proportional to the square of the impeller rotational speed, and increased exponentially to 4.6 times the eccentric ratio. When the eccentric ratio was small, the torque fluctuated due to the influence of the flow. However, when the eccentric ratio was large, the influence of the mechanical load, such as the approach of the blade to the vessel wall, generated fluctuation. Therefore, the torque fluctuated at twice the frequency of the impeller rotational speed. The standard deviation of the torque, which corresponds to the amplitude of fluctuation, was smaller than the average torque. The equation for the estimation of the torque from the impeller rotational speed and the eccentric ratio was proposed.

The horizontal load was almost zero. The load in the $y$-direction was one order larger than that in the $\mathrm{x}$ direction. The horizontal load fluctuated at the same frequency as the impeller rotational speed. From this result, it was considered probable that the mechanical effect was dominant in generating

the fluctuation in the horizontal load. The y-direction load and the resultant load in the $\mathrm{x}$ - and $\mathrm{y}$-directions were proportional to the power of the impeller rotational speed and were an exponential function of the eccentric ratio. Based on this relation, equations for estimating the horizontal load were proposed.

\section{Acknowledgement}

This research work was supported by JSPS KAKENHI Grant Number 2456092040. The MAXBLEND impeller was supplied by Sumitomo Heavy Industries Process Equipment Co., Ltd, for which we are grateful.

\section{References}

[1] Kuratsu, M., H. Nishimi, M. Mishima and T. Kamota (1987). New type mixing vessel - MAXBLEND. Sumi tomojukikai Gihou, Vol. 35, No.104.

[2] Zamzam, Z., K. Takahashi and S. Morinaga (2009). Chaotic Mixing in a Vessel Agitated by Large Impeller. J. Chem. Eng. Japan, 42, 804-809.

[3] Kikuchi, M., K. Takada and H. Itoh (1991). Flow structure and mixing characteristic in a vessel stirred with FULLZONE impeller. Shinkoupantech Gihou, Vol. 35, No.1.

[4] Yamamoto, K. and H. Nishino (1992). Kakuhan Gijutsu.: Satake Chemical Equipment Mfg Ltd.

[5] Yamamoto, K., K. Abe, A. Tarumoto, K. Nishi, M. Kaminoyama and M. Kamiwano (1998). Development and Evaluation of Large-Scale Impeller Generating Strong Circulation Flow Suitable for Wide Viscosity Range in Reactor with Cooling Coil. J. Chem. Eng. Japan, 31, 355-365.

[6] Hiruta, O, K. Yamamura, H. Takebe, T. Futamura, K. Iinuma and H. Tanaka (1997). Application of Maxblend Fermentor for microbial processes. J. Fermentation and Bioeng., 83, 79-86.

[7] Hasegawa, S., M. Nagatsuru, M. Shibutani, S. Yamamoto and S. Hasebe (1999). Productivity of concentrated hyaluronic acid using a Maxblend fermentor. J. Bioscience and Bioeng., 88, 68-71.

[8] Nagata, S. (1975). Mixing-Principles and applications.: Koudansha, Tokyo, Japan (1975)

[9] Karcz, J., M. Cudak, and J. Szoplik (2005). Stirring of a Liquid in a Stirred Tank with an Eccentrically Located Impeller. Chem. Eng. Sci., 60, 2369-2380.

[10] Nishi, K., N. Enya, R. Misumi and M. Kaminoyama (2011). Mixing in Eccentrically Located Hi-F Mixer. J. Chem. Eng. Japan, 44, 859-867. 